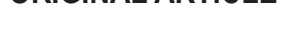

\section{Research on News Editing Skills of Radio Stations Based on New Media Era}

\author{
Qingli Meng \\ Haoguang Fashion Culture Media Co., Ltd.
}

\begin{abstract}
With the continuous development of Internet technology, the development of radio stations has encountered great challenges. Facing the current situation, how to effectively deal with the news gathering and editing work plays a vital role in the further development of radio stations. For this reason, this paper briefly analyzes the news editing skills of radio stations under the new media environment, with a view to providing some references for the radio and television industry.
\end{abstract}

Keywords: New Media; Radio Station; News Gathering and Editing; Innovation Strategy

With the popularization of mobile terminal equipment such as mobile phones and computers, the renewal of new media is becoming more and more frequent. As the throat of the Party, the government and the people, radio stations need to do a good job in cultural construction and serve the people in practical work. As an important work of radio stations, news gathering and editing must be optimized and innovated in the new media environment in order to maintain the original supporting role of radio stations.

\section{Current situation of news editing in radio stations under new media environment}

(1) It is not enough to implement the principle of "being close to life, reality and the masses". "Close to life, reality and the masses" is the basic requirement of the CPC Central Committee for news propaganda organizations. They should give full play to their due role and value and consider the social life of the people. However, according to the actual situation of radio news gathering and editing, these principles have not been effectively implemented, making people unable to accurately understand some of the government's decisions, and people's concerns have not been promptly responded to and resolved, and have not played the role of uploading and distributing. However, the important factors that influence this situation are the changes in the current media environment. On the one hand, it is impacted by the new media; on the other hand, it is due to the lack of innovation and uniformity in most news reports. Editors and editors have not carried out in-depth excavation of issues of concern to the people. This will lead to the ineffective implementation of the principle of "three approaches" and affect the long-term development of radio stations.

(2) Editors' professional quality is not high and their professional ability is poor. News gathering and editing staff of radio stations are the main force in program production. Their working ability and professional accomplishment will have a direct effect on the establishment of a good image of radio stations and the expansion of their influence. However, under the influence of other media forms, such as television, newspapers and new media, radio stations are not attractive to outstanding talents, which will lead to a lower overall quality of the editorial team and a vacancy of high-quality talents in radio stations. This will have a serious impact on the development of radio stations. Therefore, we need to find ways to improve the market competitiveness of radio stations, which requires perfecting the existing talent management system and paying attention to the construction of talent team.

Copyright (C) 2019 Qingli Meng

doi:10.18282/inm.v2i1.315

This is an open-access article distributed under the terms of the Creative Commons Attribution Non-Commercial License (http://creativecommons. org/licenses/by-nc/4.0/), which permits unrestricted non-commercial use, distribution, and reproduction in any medium, provided the original work is properly cited. 
(3) paying too much attention to economic benefits. In the current social environment, people's ideas have changed greatly. The most direct manifestation is that people pay more attention to economic income, and radio stations are no exception. No matter whether it is the emerging media or the traditional media, there is nothing wrong with the pursuit of economic income, because this is the basis for further development. Without the economic basis, nothing else is possible. However, paying too much attention to economic benefits will result in lower requirements on program quality and loss of brand value previously possessed by the program, which is very unfavorable to the long-term development of radio stations.

\section{Challenges faced by radio stations in news gathering and editing under the new media situation}

(1) The timeliness is poor, and the news content is not in place. Authenticity is the vitality of news, and timeliness is one of the important indicators of news value. freshness and explosiveness can attract the attention of the audience. Due to technical limitations, radio stations are often unable to achieve the best timeliness and cannot transmit the first-time information to the audience. At the same time, "content is king" and content is the source of news vitality. In the continuous innovation of news media, China has put forward the requirement of "three approaches", that is, news content should be close to life, reality and the masses. However, in the current development of radio stations, the requirement of "three closeness" has not been put into place, which has led to a decline in the ratings of radio stations. The reason for the existence of this problem is not only the ability of the news editors of radio stations, but also the serious impact on the requirement of "three approaches" under this new media environment.

(2) The quality of radio station editors is not high. At this stage, the effective development of China's radio stations is directly related to the editing ability of radio station editors. However, it is difficult to find high-quality talents in editing technology in the society at this stage, which is also one of the factors that radio stations are gradually heading for a downturn. Moreover, with the continuous development of new media and intense offensive, the application rate of radio stations has gradually decreased, which also clearly shows that the current radio stations are in great need of highquality talents for news gathering and editing.

(3) Narrow communication channels and fixed broadcasting time. Nowadays, the audience of radio stations is mainly composed of the elderly and some special groups. Young people are getting away from radio stations. Therefore, the audience of radio stations is small. And limited by communication channels, interaction with the audience is relatively difficult to carry out. Information can only be transmitted through sound, without the sense of picture, which makes it difficult to leave a deep impression on the audience. In addition, the audience's needs cannot be accurately grasped, which naturally reduces the attractiveness and makes it difficult to cultivate new audience groups. The new media has many communication channels and platforms, which can release news at any time and anywhere, and can also recommend news that users are interested in according to big data analysis. At the same time, the audience's role has also changed. The audience is not only the "receiver" but also the "selector". They can choose the information they want according to their own preferences. Then, the reading volume, attention and attraction of natural new media will rise accordingly.

\section{How to strengthen the radio media news editing skills under the new media}

(1) The interview method should be more flexible than before. As far as the current situation of radio stations is concerned, the traditional interview method should not be adopted for the interview method, which makes the interview content too formal and formatted. The effective innovation of the interview method is to interview different people and choose different interview methods, which makes the interview more flexible and makes the interview content more perfect than the traditional interview content. Therefore, the quality of radio stations is effectively improved, and further, the development of radio stations in China is effectively carried out.

(2) Pay attention to the depth and breadth of news, and innovate and interact with new media platforms. Under the objective environment of huge amount of news information, gathering and editing valuable news has become the first 
problem to be solved. The production of news programs needs to find "hot spots", track "hot spots" and analyze "hot spots" so as to reach from "beginning" to content and from content to special topics. The timeliness and interaction of radio programs has always been the advantage of radio stations. However, with the popularity of new media, the interactive advantage of broadcasting is weakened and the way is single. Hotline is no longer an option for listeners. The audience picked up their cell phones and put them on their lips to express their views and opinions on the social numbers set up by the radio. News editors hear the voice in the guide room, immediately listen, reduce noise, edit, and then use voice AI software to convert the voice into manuscript form, which is synchronized to the live broadcast room. The live broadcast anchor can see the manuscript of the audience's interactive content, and can broadcast the audience's voice to generate interaction. Other listeners who are listening to the program can continue to express their opinions based on the interaction of the previous listener, thus generating new interactions. In the interaction, editors can find new information at any time, track new hot spots and provide materials for programs. This is a successful case of broadcasting using Internet social APP and has become a classic mode of interactive live broadcast of broadcast news programs and various columns. This form has long been used in Hubei radio programs of various frequencies and major programs. At present, Hubei music broadcasting has also introduced an artificial voice only system, which has been put into use on an experimental basis in the noon music on-demand program of Hubei classical music broadcasting and in the local entertainment news information "good performance, listening and watching" unit. service interaction is also used as a onomatopoeia tool.

(3) The skillful use of the art of news editing. The editing process of news is an artistic editing process. In carrying out this work, we should not only carefully and scientifically set up the direction of public opinion, but also effectively arrange the overall optimization and arrangement so as to show the best to the viewers. Therefore, in the process of news editing, the most important thing is to effectively put forward the main body of the news and the topic of the news. Moreover, in the work of putting forward the main body of the news and the topic of the news, the public can better understand the answers to the relevant issues that they are concerned about in the society, so that the direction of public opinion can be correctly guided, and the simple and clear topic and content can bring the public a better viewing experience and have the function of effectively expanding the influence of public opinion. After putting forward the questions and contents, the news programs will be arranged and the program dynamics will be enriched. Such work can effectively embody the characteristics of radio stations for the masses, better enable radio stations to appear in front of the masses, and thus enable radio stations to develop better.

(4) Find the breakthrough point and increase the interaction with the audience. Finding the breakthrough point is one of the important working skills of radio station news editors. The focus of listening to radio stations is also different for different people. Therefore, in the process of editing, it is necessary to fully consider the different concerns of the audience in different regions, to be more precise and concise in content, and to be more closely related to real life in content, so that the audience can get the information they want to know in the news of radio stations. Editors and editors should search for the entry point quickly and steadily so as to better broadcast in different languages to different audiences. At the same time, under the new situation, radio station news gathering and editing should also strengthen the interactive relationship between news broadcasting and audience groups, actively communicate with the audience through various channels, increase the interesting and attractive news programs, help the development of radio stations, and effectively innovate the ability of radio station news gathering and editing skills.

\section{Conclusion}

At this stage, China's radio stations are gradually heading for a downturn. Reforming the editing skills of radio stations can effectively make radio stations stand firm in the new media environment and better provide favorable conditions for the development of radio stations.

\section{References}

1. Yu Zhang. Analysis of News Editing Skills of Radio Stations under the New Situation [J]. Research on Communication Power, 2019,3(05):99.

2. Tang Zhiyuan. News editing skills of radio stations under the new situation [J]. China Media Technology, 
2018(12):90-91.

3. Gao Yang. A Preliminary Study on the Development of Host Skills of Radio News Programs under the Background of New Media [J]. Communication Research, 2018,2(26):124.

4. Liu zhaojie. news editing skills of radio stations in the new media environment [J]. western radio and television, 2018(13):127-128.

5. Yang Shanshan. Analysis on News Editing Skills of Radio Stations in New Media Environment [J]. Cradle of Journalists, 2018(06):20-21.

6. Zhang Lijuan. News Editing Skills of Radio Stations in New Media Environment [J]. Communication Research, 2018,2(07):117. 